\title{
On the SCC behaviour of austenitic stainless steels in boiling saturated magnesium chloride solution
}

\author{
O. M. Alyousif ${ }^{1} \&$ R. Nishimura ${ }^{2}$ \\ ${ }^{I}$ Mechanical Engineering Department, Kuwait University, \\ Safat, Kuwait \\ ${ }^{2}$ Department of Applied Materials Science, Osaka Prefecture University, \\ Osaka, Japan
}

\begin{abstract}
The stress corrosion cracking (SCC) of three austenitic stainless steels was investigated as a function of test temperature and applied stress in boiling saturated magnesium chloride solutions $\left(\mathrm{MgCl}_{2}\right)$ using a constant load method. Both type 304 and type 316 exhibited similar corrosion elongation curves, while the corrosion elongation curve of type 310 was different. The relationship between the time to failure and a reciprocal test temperature fell in two straight lines on a semi-logarithmic scale as well as the relationship between the steady-state elongation rate and a reciprocal test temperature. These regions were considered to correspond to a SCC-dominated region or Hydrogen Embrittlement (HE)-dominated region. The same behaviour was observed for applied stress dependence for these stainless steels.

The relationship between the time to failure versus steady state elongation rate on a logarithmic scale became a straight line, whereas the slopes of the line for the stainless steels were different for each other. It was found that the linearity of the relationship can be used to predict the time to failure for the stainless steels in the corrosive environment. The transition time to time to failure ratio values had a different constant value for each region. From the results obtained, it may be suggested that the cracking mechanism for type 304 and type 316 was different from that for type 310 . This would be explained by whether or not a formation of martensite takes place.
\end{abstract}

Keywords: austenitic stainless steels, magnesium chloride solution, steady-state elongation rate, stress corrosion cracking, hydrogen embrittlement. 


\section{Introduction}

The stress corrosion cracking behaviour of austenitic stainless steels in chloride and other corrosive solutions has been extensively investigated using various methods [1-7]. Stress corrosion cracking in the broad sense for austenitic stainless steels is caused by either stress corrosion cracking in the narrow sense (denoted as SCC hereafter) such as active path dissolution [1-2] and film-rupture [3-4], or hydrogen embrittlement (HE) [5-7]. Austenitic stainless steels such as type 304 and 316 steels, but not type 310 steel, may undergo phase transformation from $\gamma \rightarrow \alpha^{\prime}$ martensite due to applied stress or hydrogen charging [8-9] and $\alpha^{\prime}$-martensite is considered to be directly related to brittle fracture [10]. However, the role of martensite in SCC and HE is still not fully identified. It was found that austenitic stainless steels suffered from cracking failure by two different mechanisms of SCC and HE depending upon test temperature [11].

In this study, the failure characteristics of type 304, 316 and 310 austenitic stainless steels were examined under constant loads in boiling saturated magnesium chloride solutions once with variable test temperature and constant applied stress and then with variable applied stress and at constant test temperature to evaluate the role of martensite in determining the cracking mechanism of austenitic stainless steels.

Table 1: Chemical compositions (wt $\%$ ) and mechanical properties of the austenitic stainless steels used.

\begin{tabular}{|c|c|c|c|c|c|c|c|c|c|}
\hline & $\mathrm{C}$ & $\mathrm{Si}$ & $\mathrm{Mn}$ & $\mathrm{P}$ & $\mathrm{Ni}$ & $\mathrm{Cr}$ & $\mathrm{Mo}$ & $\begin{array}{c}\sigma_{\text {Yield }} \\
(\mathrm{MPa})\end{array}$ & $\begin{array}{c}\sigma_{\text {Tensile }} \\
(\mathrm{MPa})\end{array}$ \\
\hline SS304 & 0.06 & 0.35 & 0.96 & 0.027 & 8.13 & 18.20 & - & 276 & 691 \\
\hline SS310 & 0.05 & 0.84 & 1.27 & 0.016 & 19.30 & 24.76 & - & 275 & 575 \\
\hline SS316 & 0.06 & 0.70 & 0.96 & 0.031 & 10.15 & 16.98 & 2.22 & 323 & 636 \\
\hline
\end{tabular}

\section{Experimental}

The specimens used were the commercial type 304, 316 and 310 austenitic stainless steels whose chemical compositions (wt\%) are shown in Table 1 . The geometry for stress corrosion cracking experiments is as follows: the gauge length is $25.6 \mathrm{~mm}$, the width $5 \mathrm{~mm}$ and the thickness $1 \mathrm{~mm}$. The specimens were solution-annealed at $1373 \mathrm{~K}$ for $3.6 \mathrm{ks}$ under an argon atmosphere and then water-quenched. Prior to experiments, the solution-annealed specimens were polished to 1000 grit emery paper, degreased with acetone in an ultrasonic cleaner and washed with distilled water. After the pretreatment, the specimens were immediately set into a stress corrosion cracking cell. Stress corrosion cracking tests were conducted in boiling saturated magnesium chloride solutions, the boiling temperatures of which were changed by the change in the concentration of magnesium chloride. For the experiments with variable test temperature and constant stress $(\sigma=300 \mathrm{MPa})$, the test temperature range was between $408 \mathrm{~K}$ and $428 \mathrm{~K}$. For the variable applied stress and constant test 
temperature, the applied stresses were in the range from 0 to $500 \mathrm{MPa}$ and the test temperatures used were $428 \mathrm{~K}$ (type 316), $416 \mathrm{~K}$ (type 304 and 310) and 408 $\mathrm{K}$ (type 304 and 316), where cracking failure was observed under constant applied stress condition [11]. All experiments were carried out under an open circuit condition.

\section{Results}

\subsection{Corrosion elongation curve}

Figure 1 shows the corrosion elongation curves for type 304 at $408 \mathrm{~K}$ and type 310 at $416 \mathrm{~K}$ under a constant applied stress condition $(\sigma=350 \mathrm{MPa})$ in boiling saturated magnesium chloride solutions, where the corrosion elongation curve of type 304 at $408 \mathrm{~K}$ was similar to that of type 316 at $408 \mathrm{~K}$. From these curves the three parameters were obtained for each specimen: time to failure $\left(t_{f}\right)$, steady-state elongation rate $\left(l_{s s}\right)$ for the straight part of the corrosion elongation curve and transition time to time to failure ratio $\left(t_{s s} / t_{f}\right)$, where the transition time $\left(t_{s s}\right)$ is the time when the elongation curve begins to deviate from the linear increase. For type 304 at $408 \mathrm{~K}, t_{f}$ was considerably shorter than for type 310 at $416 \mathrm{~K}$ and $t_{s s}$ was close to $t_{f}$. Thus the $t_{s s} / t_{f}$ value was close to unity. For type 310 at $416 \mathrm{~K}, t_{s s}$ was approximately half the time to failure.

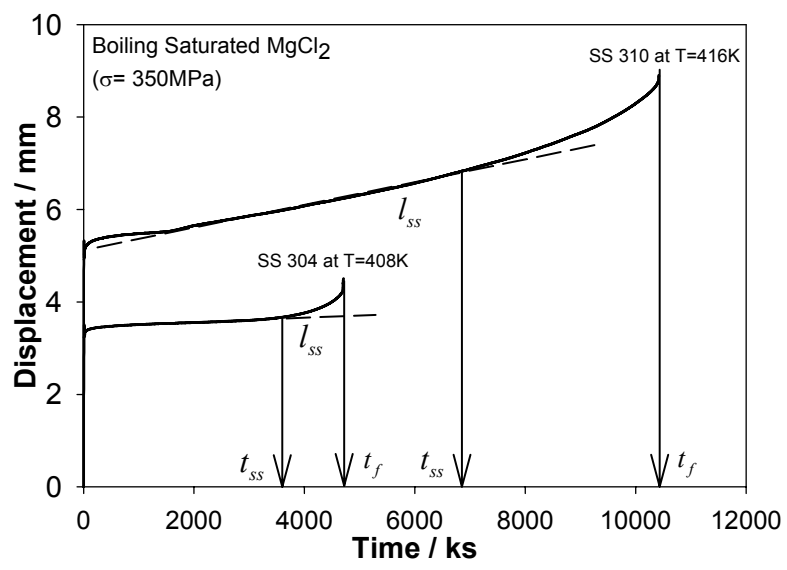

Figure 1: Corrosion elongation curves for type 304 steel at $408 \mathrm{~K}$ and type 310 steel at $416 \mathrm{~K}$ under a constant applied stress condition $(\sigma=$ $350 \mathrm{MPa}$ ) in boiling saturated $\mathrm{MgCl}_{2}$ solutions. 


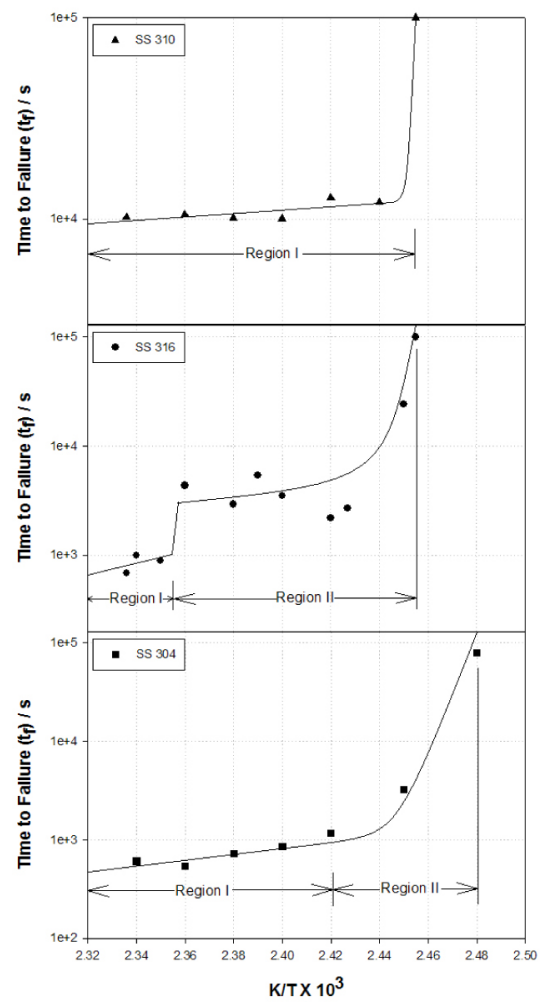

(a)

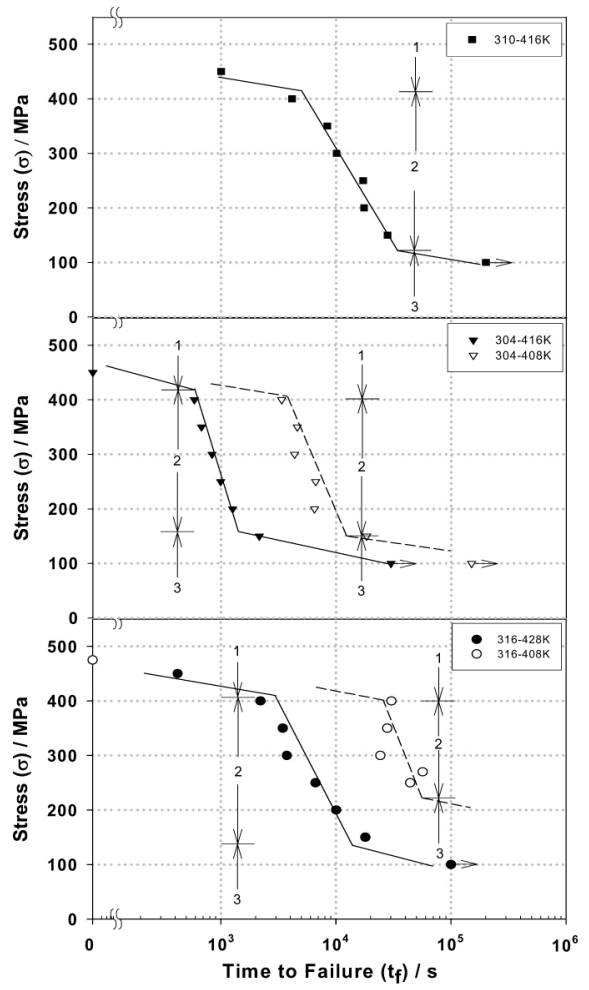

(b)

Figure 2: The logarithms of $\left(t_{f}\right)$ versus the reciprocal of the test temperature $(1 / \mathrm{T})(\mathrm{a})$ and Applied stress $(\sigma)$ versus $t_{f}$ (b) for type 310, 304 and 316 steels in boiling saturated $\mathrm{MgCl}_{2}$ solutions.

\subsection{Effects of test temperature and applied stress on $t_{f}$}

Figure 2 (a) depicts the logarithm of $t_{f}$ versus the reciprocal of the test temperature for the three stainless steel types used in the experiments. For type 304 , the relationship between $t_{f}$ and $1 / \mathrm{T}$ falls in a straight line, shown as region-I, until a test temperature of about $413 \mathrm{~K}\left(1 / \mathrm{T}=2.42 \times 10^{-3}\right)$, below which the relationship deviates from the linearity. The region from $413 \mathrm{~K}(1 / \mathrm{T}=$ $\left.2.42 \times 10^{-3}\right)$ to a threshold test temperature, approximately $403 \mathrm{~K}\left(1 / \mathrm{T}=2.48 \times 10^{-}\right.$ ${ }^{3}$ ), below which little fracture takes place within a laboratory time scale, was called region-II. For type 316 , the parameter $t_{f}$ was also grouped into two regions; region-I at test temperatures above $424 \mathrm{~K}\left(1 / \mathrm{T}=2.36 \times 10^{-3}\right)$ and region-II with test temperatures below $424 \mathrm{~K}\left(1 / \mathrm{T}=2.36 \times 10^{-3}\right)$ up to a threshold test 
temperature of about $408 \mathrm{~K}\left(1 / \mathrm{T}=2.45 \times 10^{-3}\right)$. The $t_{f}$ values of type 310 showed slight sensitivity to test temperature. The $t_{f}$ values for type 310 were grouped in a straight line which constitutes region-I until a threshold test temperature of about $408 \mathrm{~K}\left(1 / \mathrm{T}=2.45 \times 10^{-3}\right)$ without region-II. Therefore, in Figure 1, the elongation curve for type 310 at $416 \mathrm{~K}\left(1 / \mathrm{T}=2.40 \times 10^{-3}\right)$ falls in region-I, while that for type 304 at $408 \mathrm{~K}\left(1 / \mathrm{T}=2.45 \times 10^{-3}\right)$ falls in region-II.

Figure 2 (b) depicts applied stress $\sigma$ versus logarithm of $t_{f}$ for the three stainless steels at three test temperatures used. All relationships can be divided into three regions shown by Arabic numerals 1-3 in Figure 3; region 1 is the stress-dominated failure region, region 2 the stress corrosion cracking SCCdominated failure region and region 3 the corrosion-dominated failure region. In region $2, t_{f}$ values for type 304 at $416 \mathrm{~K}$ and for type 316 at $428 \mathrm{~K}$ are shorter than those at $408 \mathrm{~K}$ and $t_{f}$ for type 304 is shorter than that for type 316 . In addition, the applied stress range in region 2 for type 316 at $408 \mathrm{~K}$ is narrower than that for type 304 at $408 \mathrm{~K}$; the maximum applied stress in region 2 is the same for both steels, but the minimum applied stress for type 316 is higher than that for type 304. At higher temperatures, the applied stress range in region 2 is almost the same for these stainless steels. It was also found that the behaviour of the steady state elongation corresponded to those in Figure 2 and the value of $t_{s s} / t_{f}$ was different depending upon region; 0.57 in region I and 0.63 in region II.

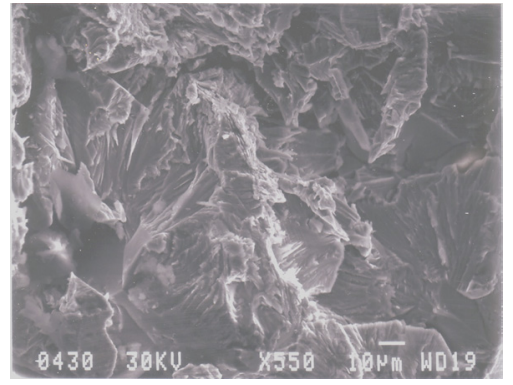

(a)

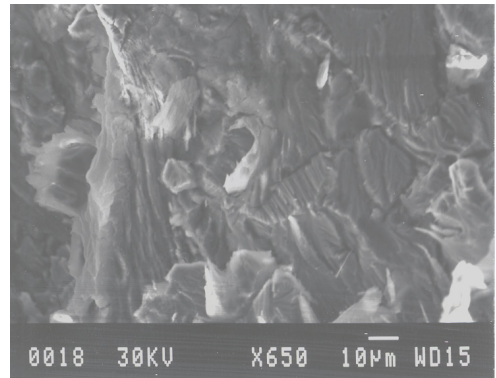

(b)

Figure 3: $\quad$ Fracture appearances for type 304 steel at $416 \mathrm{~K}$ and $\sigma=300 \mathrm{MPa}$; $\mathrm{X} 550$ (a) and for type 310 steel at $416 \mathrm{~K}$ and $\sigma=300 \mathrm{MPa}$; X650 (b) in boiling saturated $\mathrm{MgCl}_{2}$ solutions.

\subsection{Fracture appearance}

Figure 3 shows the fracture appearances of type 304 (a) and 310 (b) in region 2 at $416 \mathrm{~K}$. The fracture mode for type 304 and 310 is predominantly transgranular. The transgranular fracture was observed over the whole test 
temperatures in region I and the whole applied stresses in region 2. Type 316 in region 2 at $428 \mathrm{~K}$ exhibited the same transgranular fracture appearance as those in Figure 6. On the other hand, as shown in Figure 4, the fracture appearance in region 2 for type 316 at $408 \mathrm{~K}$ and all test temperatures in region II (408 K-423 $\mathrm{K}$ ) is a mixture of intergranular and transgranular modes (a) at a low applied stress (300 $\mathrm{MPa})$ and predominantly intergranular mode (b) at a high applied stress $(400 \mathrm{MPa})$. The ratio of intergranular appearance to transgranular one increased with increasing applied stress in region 2 and finally the fracture mode became completely intergranular. The fracture appearances for type 304 at 408 $\mathrm{K}$ and at all temperatures in region II were mostly intergranular and almost the same as those for type 316 . For type 310 , the fracture mode was transgranular over the whole applied stresses and at all test temperatures in region 2.

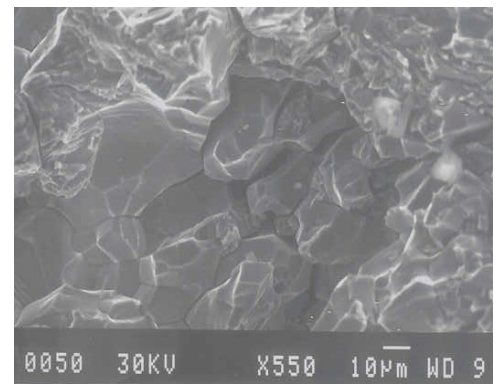

(a)

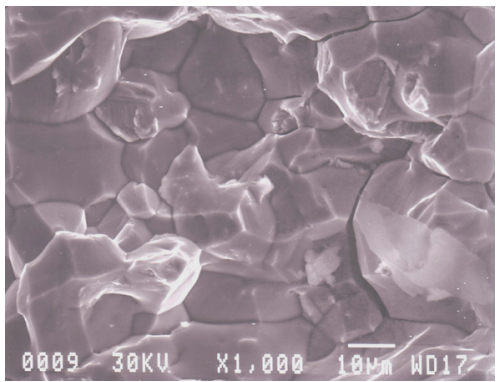

(b)

Figure 4: $\quad$ Fracture appearances for type 316 steel at $408 \mathrm{~K}$ and $\sigma=300 \mathrm{MPa}$; X550 (a) and for type 316 steel at $408 \mathrm{~K}$ and $\sigma=400 \mathrm{MPa}$; 1000 (b) in a boiling saturated $\mathrm{MgCl}_{2}$ solution.

\section{Discussion}

\subsection{Characteristics of stress corrosion cracking}

In the applied stress region where the SCC-dominated failure occurred, the fracture mode for type 304 and 316 at 416 and $428 \mathrm{~K}$ was transgranular, while that at $408 \mathrm{~K}$ was mostly intergranular, in particular at higher applied stresses. In other words, for type 304 and 316 in boiling magnesium chloride solutions, the fracture mode was transgranular at higher temperatures and intergranular at the lower temperature. For type 310 only transgranular fracture was found as far as stress corrosion cracking occurred in any temperatures in boiling magnesium chloride solutions [11]. The minimum applied stress to induce intergranular cracking for type 316 was significantly higher than that for type 304 . In general, transgranular cracking was characterized by a higher rate of elongation in both SCC-dominated and stress-dominated regions and shorter time to failure. By contrast the failure in intergranular cracking was slow and most of the time to failure was in the steady state elongation region indicating the small mechanical 
elongation until failure. Consequently, intergranular cracking for these austenitic stainless steels in the boiling magnesium chloride solution revealed more brittle nature in comparison with transgranular cracking.

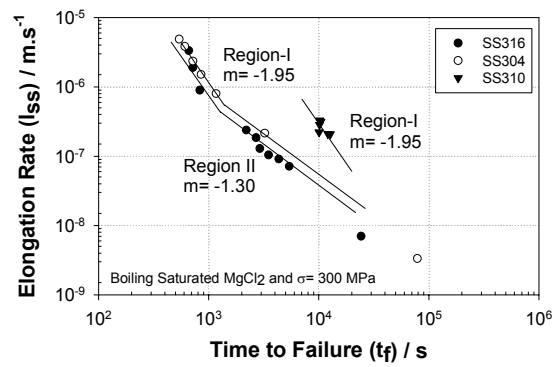

(a)

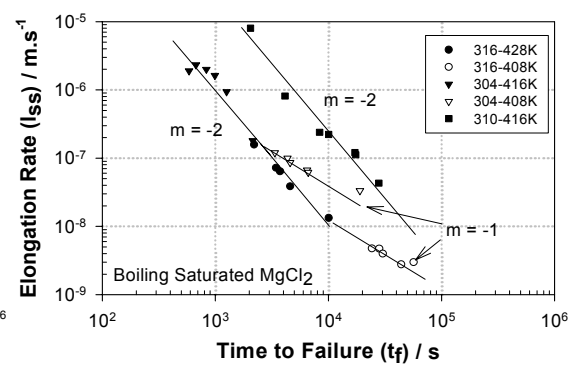

(b)

Figure 5: The relation between time to failure $\left(t_{f}\right)$ and the logarithms of $\left(l_{s s}\right)$, where $\mathrm{m}$ is the slope of the straight line. (a) for constant stress and variable test temperature and (b) for constant test temperature and variable stress.

\subsection{A parameter for predicting time to failure}

As shown in Figure 5 (a), the $\log -t_{f}$ versus $\log -l_{s s}$ relationship for types 304 and 316 obtained as a function of test temperature became two straight lines with the slopes of $\mathrm{m}=-1.95$ and $\mathrm{m}=-1.30$, where the former value was in region-I in Figure 2 (a) and the latter in region-II in Figure 2 (a). In the case of type 310, the $\log -t_{f}$ versus $\log -l_{s s}$ relation for type 310 became a single straight line with slope $\mathrm{m}=-1.95$. Figure 5 (b) shows the relationships between the logarithm of $l_{s s}$ and logarithm of $t_{f}$ in region 2 in Figure 2 (b) for all stainless steels. The $\log l_{s s}$ versus $\log t_{f}$ curves in region 2 for types 304 and 316 become two straight lines with a slope of $\mathrm{m}=-2$ at 418 and $428 \mathrm{~K}$ and with a slope of $\mathrm{m}=-1$ at $408 \mathrm{~K}$, and type 310 also shows a straight line with $\mathrm{m}=-2$. Thus, the empirical equations for the stainless steels are as follows:

For type 304 and 316 at higher temperatures and type 310 steel in region 2 at constant stress or constant temperature conditions

$$
\log l_{s s}=-2 \log t_{f}+\mathrm{C}_{1}
$$

For type 304 and 316 in region 2

$$
\log l_{s s}=\mathrm{m} \log t_{f}+\mathrm{C}_{2}
$$

where $\mathrm{m}=-1.3$ for constant stress condition and $\mathrm{m}=-1.0$ for constant temperature condition. $\mathrm{C}_{1}$ and $\mathrm{C}_{2}$ are constants and depend on material. It can be seen in Figure 8 that type 304 at $416 \mathrm{~K}$ and type 316 at $428 \mathrm{~K}$ show the same $\mathrm{C}_{1}$ 
value, although type 310 steel shows different $C_{1}$ value, and that the $C_{2}$ value of type 304 at $408 \mathrm{~K}$ is different from that of type 316 .

In addition to these characteristics, it can be said that steady-state elongation rate $\left(l_{s s}\right)$ is a useful parameter for predicting the time to failure $\left(t_{f}\right)$ independent of applied stress even in boiling saturated magnesium chloride solutions as well as in hydrochloric and sulphuric acid solutions [13-14], because $l_{s s}$ can be obtained at a time within $10-20 \%$ of $t_{f}$ from the corrosion elongation curve.

\subsection{A qualitative explanation of fracture mechanism}

Type 304 is a metastable austenite and is highly susceptible to martensite formation [16]. Type 316 is also a metastable austenite and is moderately susceptible to martensite formation [17]. On the other hand, type 310 is known to be less susceptible to martensite formation [18]. For metastable austenitic stainless steels like types 304 and 316, the strain-induced formation of martensite tends to take place along grain boundaries and particularly is facilitated by hydrogen entry [19-20]. The presence of martensite is known to induce hydrogen embrittlement (HE) because of very high hydrogen diffusivity coefficient and very small hydrogen content compared to those of the austenite [17]. Thus, martensite formed at grain boundaries is apt to be responsible for $\mathrm{HE}$ of intergranular mode, and types 304 and 316 have higher susceptibility to martensite-induced HE of intergranular mode, but type 310 has little susceptibility to martensite-induced HE of intergranular mode.

On the other hand, transgranular cracking is caused by propagation of cracks nucleated at slip steps and is not related to martensite formed at grain boundaries. Thus stress corrosion cracking in the narrow sense of the word (SCC) includes such transgranular cracking.

Types 304 and 316 suffered intergranular cracking at a lower temperature $(408 \mathrm{~K})$ and transgranular cracking at higher temperatures $(428 \mathrm{~K}$ for type 316 and $416 \mathrm{~K}$ for type 304). In determining the cracking mode a competition between dissolution of material at slip steps inducing SCC and hydrogen entry inducing $\mathrm{HE}$ is the decisive factor as well as the formation of martensite. The hydrogen entry is determined by the difference between hydrogen absorption and hydrogen escape. Transgranular SCC for types 304 and 316 was caused by propagation of cracks nucleated at slip steps, not at martensite at grain boundaries [21]. Therefore, the cracking mode would be determined by the competition between the dissolution rate at slip steps and the hydrogen entry rate at grain boundaries with martensite. As test temperature increases, the dissolution rate increases. On the other hand, both hydrogen absorption rate and hydrogen escape rate increase with increasing test temperature, whereas the amount of hydrogen entry decreases, because the hydrogen escape rate becomes superior to the hydrogen entry rate with increasing temperature. This means that the amount of hydrogen entry decreases with increasing test temperature [22]. In addition, it is considered that the amount of martensite decreases with increasing 
test temperature, which suggests that the hydrogen entry rate decreases with increasing test temperature [23]. Thus, the dissolution rate becomes higher than the hydrogen entry rate at higher temperatures. This will result in transgranular $\mathrm{SCC}$ at higher temperatures.

On the other hand, it is known that the amount of martensite increases with strain or applied stress [17]. At $408 \mathrm{~K}$ for types 304 and 316, the fracture mode changed from a mixed transgranular and intergranular mode to a complete intergranular mode with increasing applied stress. If cracking failure at $408 \mathrm{~K}$ is caused by martensite-induced $\mathrm{HE}$, the increase in intergranular mode with increasing applied stress is in agreement with an increase in the amount of martensite with increasing applied stress. Similarly, the minimum applied stress to induce intergranular cracking for type 316 steel was significantly higher than that for type 304 in agreement with the fact that type 316 is less susceptible to stress-induced martensite formation than type 304. Furthermore, type 304 was more susceptible to intergranular cracking in comparison with type 316 in agreement with the fact that type 304 has the higher susceptibility to straininduced martensite formation in comparison with type 316.

Consequently, intergranular cracking observed at the lower temperature, that is, $408 \mathrm{~K}$ for types 304 and 316 is due to grain boundary martensite-induced hydrogen embrittlement (HE) and transgranular cracking for types 304 and 316 at higher temperatures at 416 and $428 \mathrm{~K}$ and for 310 is ascribed to stress corrosion cracking in the narrow sense of the word (SCC).

\section{Conclusions}

The stress corrosion cracking behaviour of three austenite stainless steels with different susceptibilities to stress-induced martensite formation was examined in boiling saturated magnesium chloride solutions with different boiling temperatures under constant load condition. The following conclusions can be drawn:

(1) The cracking mechanism for type 304 was transgranular at a higher test temperature more than $413 \mathrm{~K}$ and intergranular at a lower test temperature less than $412 \mathrm{~K}$. The cracking mechanism for type 316 was transgranular at a higher test temperature more than $424 \mathrm{~K}$ and a mixture of transgranular and intergranular cracking at a lower test temperature less than $424 \mathrm{~K}$. The cracking mechanism for type 310 was transgranular at test temperatures higher than $408 \mathrm{~K}$ and no intergranular cracking behaviour was observed.

(2) The relationships between $\log l_{s s}$ and - $\log t_{f}$ for types 304, 316 and 310 became a good straight line. Their slopes depended upon fracture mode; -2 for SCC and -1 or -1.30 for HE.

(3) It was estimated that HE occurred by martensite formed along the grain boundaries with hydrogen entry, while SCC took place by a propagating crack nucleated at slip step by dissolution. 


\section{References}

[1] T.P. Hoar \& J.C. Scully, J. of Electrochemistry, 111, pp. 348-352, 1964.

[2] R. Nishimura \& Y. Maeda, Corrosion Science, 46, pp. 343-355, 2004.

[3] T. Nakayama \& M. Takano, Corrosion, 42, pp. 10-14, 1986.

[4] M.B. Whiteman \& A.R. Troiano, Corrosion, 21, pp. 53-56, 1965.

[5] M.L. Holzworth, Corrosion, 25, pp. 107-115, 1969.

[6] P.R. Rhodes, Corrosion, 25, pp. 462-467, 1969.

[7] H. Hanninen \& T. Hakkarainen, Metallurgical Transactions A, 10A, pp. 1196-1199, 1979.

[8] N. Narita, C.J. Altstetter \& H.K. Birnbaum, Metallurgical Transactions A, 13A, pp. 1355-1365, 1982.

[9] J.C. Scully, The role of hydrogen in stress corrosion cracking, eds. A.W. Thompson \& I.M. Bernstein, Effect of Hydrogen on Behavior of Materials, AIME, pp.129, 1975.

[10] O. M. Alyousif \& R. Nishimura, Corrosion Science, 48, pp. 4283-4293, 2006.

[11] R. Nishimura \& H. Sulaiman, Stress corrosion cracking of sensitized type 316 austenitic stainless steel in pure sulfuric acid solution, $12^{\text {th }}$ Int. Corrosion Congress: Corrosion control for low cost reliability, pp. 4325, 1993.

[12] R. Nishimura \& K. Kudo, Corrosion, 45, pp. 308-316, 1989.

[13] R. Nishimura, Corrosion Science, 34, pp. 1859-1868, 1993.

[14] R. Nishimura, Corrosion Science, 34, pp. 1463-1473, 1993.

[15] C.L. Briant, Metallurgical Transactions A, 10A, pp. 181-189, 1979.

[16] X. Sun, J. Xu \& Y. Li, Acta Metallurgica, 37, pp. 2171-2176, 1989.

[17] S.S. Birley \& D. Tromans, Corrosion, 27, pp. 63-71, 1971.

[18] T-P. Perng \& C.J. Altstetter, Acta Metallurgica, 34, pp. 1771-1781, 1986.

[19] H. Hanninen \& T. Hakarainen, Corrosion, 36, pp. 47-51, 1980.

[20] R. Nishimura, Corrosion, 46, pp. 311-318, 1990.

[21] J.K. Tien, Diffusion and the dislocation sweeping mechanism, Effect of Hydrogen on Behavior of Materials, eds. A.W. Thompson \& I.M. Bernstein, AIME, pp.309, 1975.

[22] R.E. Reed-Hill, Physical Metallurgy Principles, second ed., Brooks/Cole Engineering Division, pp. 656, 1973. 